\title{
Sistem Informasi Data Pegawai Berbasis Web Pada Kementerian Kelautan Dan Perikanan Kota Ternate
}

\author{
Muhdar Abdurahman \\ Program Studi Manajemen Informatika \\ Akademi Ilmu Komputer Ternate (AIKOM) Ternate \\ muhdarabdurahman@gmail.com
}

\begin{abstract}
Abstrak
Kementerian Kelautan dan Perikanan Nusantara Ternate merupakan salah satu instansi pemerintah yang ada pada kota ternate pada bidang Kelautan dan Perikanan, dalam mengelola dan media menyimpan informasi yang berhubungan dengan data, profil dan kegiatan pegawai masih dilakukan secara manual. Pendataan secara manual dianggap tidak efektif serta membutuhkan waktu, di saat melakukan pengecekan dan pencarian data-data pegawai tersebut harus membuka satu persatu Arsip Pegawai. Penelitian ini dilakukan pada Kementerian Kelautan dan Perikanan Nusantara Ternate, Sistem yang dirancang berbasis Web sebagai media untuk informasi kepada masyarakat, Bahasa Pemrograman yang digunakan adalah HTML, PHP, CSS dan MySQL sebagai database, diharapkan mempermudah Admin dalam mengelola data pegawai secara efesien dan media informasi kepada masyrakat pada Kelautan dan Perikanan
\end{abstract}

Kata Kunci : Sistem Informasi, Data Pegawai, Web

\section{Abstract}

The Office of the Ministry marine and fisheries of the archipelago Ternate City is one of the Government agencies that are in the city of ternate on the fields of marine and Fisheries. in managing and storing media information related to data, profiles and employee activities are still carried out manually, Manually logging is considered ineffective and takes, at the time of checking and search the employee data should open one by one Employee Archive. This research was conducted in Ministry of marine and fisheries of the archipelago Ternate City, Web-based system designed as a medium for information to the public, The programming language used is HTML, CSS, PHP and MySql as a database, expected to facilitate Admin in managing employee data are efficiently and media information to communities on marine and Fisheries

Keywords: Information System, Employee Data, Website

\section{PENDAHULUAN}

Teknologi dan informasi merupakan dua hal yang tidak dapat dipisahkan. Hal ini terlihat dari proses untuk mendapatkan informasi yang dapat diperoleh secara cepat, tepat, dan akurat dengan didukung oleh kemajuan teknologi yang semakin canggih. Kemajuan teknologi ini membuat banyak organisasi dan instansi menggunakan teknologi berbasis komputer dan jaringan untuk membantu pekerjaannya karna bersifat efektif dan efisien.

Banyak lembaga atau instansi yang telah menggunakan sistem dalam mengolah datanya. Pengembangan jaringan komunikasi data antara Komputer menjadikan internet muncul dengan berbagai aplikasi. Internet dengan aplikasi pada dasarnya adalah media yang digunakan untuk mengefisiensikan proses komunikasi. Kantor Kementerian dan Kelautan Perikanan Nusantara Ternate 
merupakan salah satu organisasi atau instansi yang memiliki sistem yang komplit dalam pengolahan datanya, yang menharuskan semua data di olah dengan baik, tersimpan dengan rapi dan mudah ditelusuri dari tempat penyimpanannya apabila diperlukan.

Kantor Kementerian Kelautan dan Perikanan Nusantara Ternate proses penyimpanan informasi yang berhubungan dengan kegiatan para pegawai masih dilakukan secara manual. Pendataan sering kali tidak efektif serta membutuhkan waktu yang cukup lama ketika melakukan pengecekan terhadap data-data pegawai. Kementerian dan Kelautan Perikanan Nusantara Ternate belum memiliki Website resmi sebagai media informasi yang bisa diketahui lansung oleh masyarakat, khususnya informasi mengenai data-data pegawai yang ada di kementerian dan kelautan perikanan nusantara Ternate sehingga pengolahan datanya belum efektif.

\section{Rumusan Masalah}

Bagaimana merancang Sistem Informasi data Pegawai Berbasis Web pada Kementerian Kelautan dan Perikanan agar mempermudah admin dalam mengelola data pegawai secara cepat

\section{Tujuan Penilitian}

Tujuan dari Penelitian ini adalah Merancang Sistem Informasi Data Pegawai Berbasis Web pada Kementerian Kelautan dan Perikanan

\section{Manfaat Penilitian}

Manfaat dari penelitian adalah Mempermudah admin mengelola data pegawai pada sistem secara cepat serta media informasi kepada masyarakat tentang perikanan dan kelautan

\section{Tinjauan Pustaka}

Menurut Penelitian Nofyat, Adelina, Arisandy Ambarita dengan judul Sistem Informasi Pengaduan Pelanggan Air Berbasis website Pada PDAM Kota Ternate mengatakan bahwa Perusahaan Daerah Air Minum (PDAM) Kota Ternate merupakan Badan Usaha Milik Daerah (BUMD) yang pelayanan pengaduan air kepada pelanggan masih bersifat konvensional dimana pelanggan yang ingin mengadukan keluhannya harus datang ke kantor unit wilayah PDAM Kota Ternate proses penggaduanpun hanya dapat dilakukan pada hari kerja yaitu Senin - Jumat mulai dari Pukul 07.30 15.00 wit. Diluar waktu tersebut pelanggan tidak dapat menyampaikan keluhannya sehingga dianggap kurang efektif. Penilitian tersebut bertujuan untuk merancang Sistem Informasi Pengaduan Pelanggan Air Berbasis Web. dengan adanya sistem ini diharapkan mempermudah pelanggan dalam mengadukan keluhan air di manapun dan kapanpun tanpa harus datang ke kantor PDAM Kota Ternate

Menurut Vivin Ambar dan Arisandy Ambarita pada Judul Sistem Informasi Data Kelulusan Siswa Non-Formal Berbasis Web Pada Dinas Pendidikan Nasional Kota Ternate, mengatakan bahwa Dinas Pendidikan Nasional Kota Ternate merupakan salah satu instansi pemerintah yang berperan penting dalam mengimplementasi pelayanan pendidikan non-formal dibidang PNFI (Pendidikan Non-Formal dan Informal). Dalam Pengolahan data hasil kelulusan siswa non-formal pada Dinas Pendidikan Nasional masih bersifat konvensional, dimana proses penginputan, penyimpanan dan informasi hasil kelulusan masih 
dilakukan secara manual dan tertulis. Proses pencarian data hasil kelulusan siswa membutuhkan waktu yang sangat lama dikarenakan data hasil kelulusan siswa tersimpan pada arsip-arsip dan harus dibuka satu per satu, dan informasi hasil kelulusan masih diumumkan di papan pengumuman pada Dinas Pendidikan Nasional, sehingga siswa harus datang untuk melihat hasil pengumuman tersebut. Penilitian tersebut memberikan kemudahan pihak instansi untuk melakukan pengolahan data hasil kelulusan siswa non-formal dan mempermudah siswa dan orang tua untuk dapat melihat informasi hasil kelulusan pada website

\section{LANDASAN TEORI}

\section{Pengertian Sistem}

Sistem umumnya diartikan sebagai satu kesatuan yang utuh. Menurut Mulyanto (2009), sistem adalah kumpulan dari sub-sub system baik abstrak maupun fisik yang saling terintegrasi dan salin berkolaborasi untuk mencapai suatu tujuan tertentu. Al Fatta (2013) mendefenisikan sistem sebagai sekelompok elemen-elemen yang terintegrasi dengan maksud yang sama untuk mencapai suatu tujuan. Secara garis besar, sebuah sistem informasi terdiri atas tiga komponen utama. Ketiga komponen tersebut mencakup software, dan brainware. Ketiga komponen ini saling berkaitan satu sama lain. Dari definisi tersebut dapat disimpulkan bahwa sistem adalah kumpulan dari elemenelemen yang saling berinteraksi dan saling berhubungan satu sama lainnya untuk mencapai suatu tujuan

\section{Karakteristik Sistem}

Sistem mempunyai beberapa karakteristik atau sifat-sifat tertentu, yang terdiri dari:

1. Komponen sistem (Component), adalah suatu system terdiri dari sejumlah komponen yang saling berinteraksi, yang saling bekerja sama membentuk suatu komponen system attau bagian-bagian dari system.

2. Batasan system (Bondry), adalah daerah yang membatasi sesuatu system dengan system yang lain atau lingkungan kerjanya.

3. Penghubung system (Interface), media penghubung antara suatu subsistem dengan subsistem lain. Adanya penghubung ini memungkinkan berbagai sumber daya mengalir dari satu subsistem ke subsistem lainnya.

4. Sasaran sistem (Objek), adalah tujuan yang ingin dicapai oleh system, akan dikatakan berhasil apabila mengenai sasaran atau tujuan.

Pengolahan sistem (proses), adalah suatu system dapat mempunyai suatu bagian pengolah yang akan mengubah masukan menjadi keluaran.

\section{Pengertian Sistem Informasi}

Sistem informasi merupakan gabungan dari pengertian sistem dan informasi sebagaimana uraian di atas. Jogiyanto (2005) memberikan definisi terhadap system informasi sebagai berikut: "Sistem informasi adalah suatu system di dalam suatu organisasi yang mempertemukan kebutuhan pengolahan transaksi harian, mendukung operasi, bersifat manejerial dan kegiatan strategi dari suatu organisasi dan menyediakan pihak luar tertentu dengan laporan-laporan yang diperlukan". Sedangkan menurut Sutarbi (2012) sistem informasi adalah suatu system di dalam organisasi yang mempertemukan 
kebutuhan pengelolaan transaksi harian yang mendukung fungsi organisasi yang manejerial dalam kegiatan srtategi dari suatu organisasi untuk dapat menyediakan pihak luar tertentu dengan laporan-laporan yang di perlukan. Sistem informasi yang ditulis oleh Taufiq (2013) dapat dijelaskan sebagai berikut: "Sistem informasi adalah kumpulan dari sub-sub sistem yang saling terintegrasi dan berkolaborasi untuk menyelesaikan masalah tertentu dengan cara mengolah data dengan alat namanya komputer sehingga memiliki nilai tambah dan bermanfaat bagi pengguna".

\section{Pengertian Data}

Data adalah fakta mengenai objek data juga dapat didefenisikan sebagai bahan keterangan tentang kejadian-kejadian atau fakta yang dirumuskan dalam sekelompok lembaga tertentu yang tidak di acak yang menunjukan jumlah, tindakan, kejadian, aktivitas dan transaksi yang tidak mempunyai makna atau tidak berpengaruh secara lansung kepada pemakai, (Sutabri, 2012).

\section{Pengolahan Data}

Pengolahan data merupakan bahan mentah untuk di olah yang hasilnya kemudian menjadi informasi. Dengan kata lain, data yang telah di peroleh harus di ukur dan di nilai baik dan buruk, berguna atau tidak dalam hubungannya dengan tujuan yang akan di capai, (Sutabri, 2012). Ada beberapa operasi yang dilakukan dalam pengolahan data, antara lain sebagai berikut:

1. Data masukan yaitu kumpulan data transaksi ke sebuah pengolahan data medium ke dalam kalkulator, merupakan data masukan. Contoh lain dari data masukan adalah pengkodean dari data transaksi ke dalam bentuk lain.

2. Data transformasi, beberapa bentuk data transformasi diantaranya adalah sebagai berikut:

a. Kalkulasi operasi aritmatik terhadap field

b. Menyimpulkan proses akumulasi beberapa data, misalkan menjumlahkan jam kerja per minggu.

3. Informasi keluaran, menampilkan hasil merupakan kegiatan untuk menampilkan informasi yang di butuhkan pemakai monitor atau cetakan, sedangkan reproducing (memproduksi ulang) merupakan kegiatan penyimpanan data yang digunakan untuk pemakai lain yang membutuhkan Telecommunicating (telekomunikasi) adalah kegiatan penyimpanan data secara elektronik melalui saluran komunikasi, (Sutabri, 2012).

\section{Pengertian Pegawai PNS dan Pegawai Kontrak}

Pegawai Negeri adalah mereka yang setelah memenuhi syarat-syarat yang di tentukan dalam peraturan perundangundangan yang berlaku, diangkat oleh pejabat yang berwenang dan diserahi tugas dalam sesuatu jabatan Negeri atau diserahi tugas Negara Lainnya yang di tetapkan berdasarkan sesuatu peraturan perundangundangan dan di gaji menurut peraturan perundang-undangan yang berlaku.

Pegawai kontrak adalah pegawai yang di perbantukan untuk menyelesaikan pekerjaan-pekerjaan rutin perusahaan, dan tidak ada jaminan kelangsungan masa kerjanya. Dalam kelangsungan masa kerja kontrak di tentukan oleh prestasi kerjanya. Semakin bagus prestasi kerjanya, pegawai 
kontrak akan di pertahankan oleh instansi, namun jika prestasi kerjanya tidak ada peningkatan maka instansi akan memberhentikan pegawai tersebut.

\section{Pengertian MySQL}

Menurut Saputra (2011) secara umum, database berfungsi sebagai tempat atau wadah untuk menyimpan, mengklasifikasikan profesional. MySQL bekerja menggunakan SQL Language (Struktur Query Language). Itu dapat diartikan bahwa MySQL merupakan standar penggunaan database di dunia untuk mengelolah data

\section{Pengertian PHP}

Saputra (2011), PHP atau yang memiliki kepanjangan PHP Hypertext Preprocessor merupakan suatu bahasa pemograman yang difungsikan untuk membangun suatu website dinamis. PHP berjalan pada sisi server sehingga PHP disebut juga sebagai bahasa Server Side Scripting. Artinya bahwa dalam setiap/untuk menjalankan PHP wajib adanya seb server

\section{Konsep Pemodelan Sistem}

\section{Flowchart}

Flowchart adalah bagan-bagan yang mempunyai arus yang menggambarkan langkah-langkah penyelesaian suatu masalah. penggambaran secara grafik dari langkah-langkah dan urut-urutan prosedur dari suatu program. Flowchart menolong analis dan programmer untuk memecahkan masalah kedalam segmen-segmen yang lebih kecil dan menolong dalam menganalisis alternatif-alternatif lain dalam pengoperasian
Data flow diagram sering digunakan untuk menggambarkan suatu sistem yang telah ada atau sistem baru yang akan dikembangakan secara logika tanpa mempertimbangkan lingkungan fisik dimana data tersebut mengalir (misalnya lewat telepon, surat dan sebagainya) atau lingkungan fisik diman data tersebut akan tersimpan (misalnya file kartu, microfiche, hard disk, tape, disket dan lain sebagainya).

\section{Entity Relationship Diagram (ERD)}

Entity Relationship Diagram merupakan gambaran sistematis model data yang berisi himpunan entitas dan himpunan relasi yang masing-masing dilengkapi dengan atribut-atribut yang mempresentasikan seluruh fakta.

\section{METODE PENELITIAN}

\section{Jenis dan Sumber Data}

Penelitian ini menggunakan Data Sekunder berupa dokumen-dokumen yang diperoleh lansung dari Kementerian Kelautan dan Perikanan Nusantara Ternate.

Data Sekunder adalah data yang diperoleh melalui instansi terkait yang berupa dokumen-dokumen atau referensi yang berkaitan dengan masalah yang di telitih.

\section{ANALISIS DAN PERANCANGAN}

\section{Analisa sistem yang berjalan}

Sistem yang berjalan merupakan sistem yang masih manual dalam mengelola data pegawai, diantaranya penginputan data-data pegawai

\section{Data Flow Diagram}




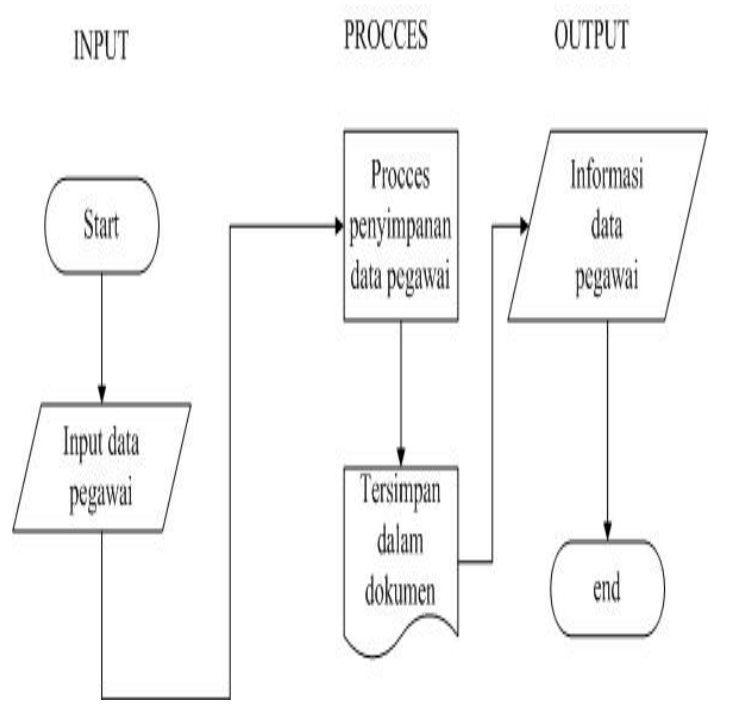

Gambar 1. Flowchart Sistem Yang

Berjalan

\section{Rancangan system yang di usulkan}

Sistem yang di usulkan merupakan sistem yang baru dalam mengelola data Pegawai, berikut alur sistem yang di usulkan

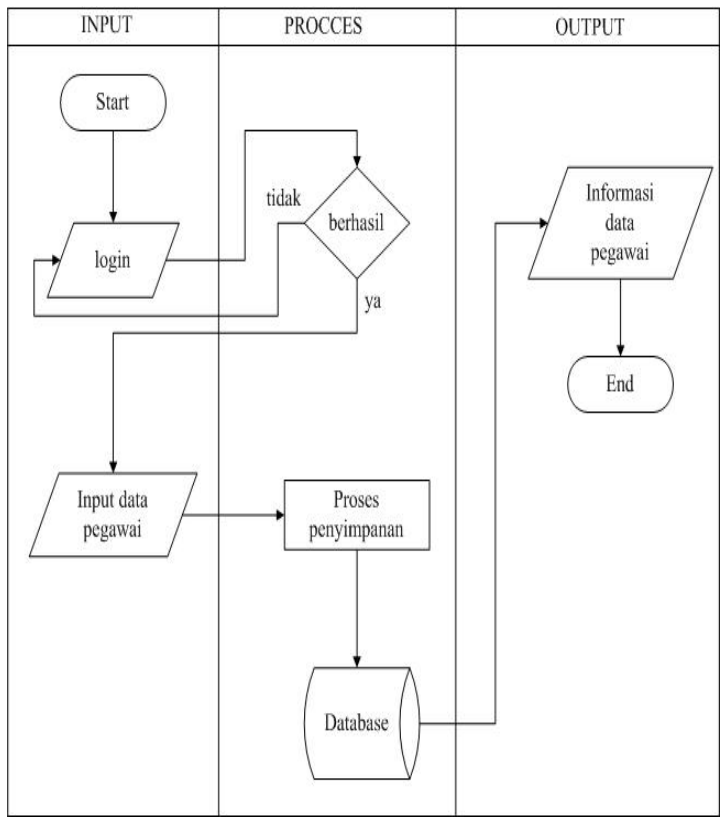

Gambar 2. Flowchart Sistem Yang

Diusulkan d. RAM 2 GB DDR3

e. Hardisk $350 \mathrm{~GB}$

f. Mouse

g. Keyboard

h. Printer Cannon IP2700

2. Perangkat Lunak (Software)

a. Sistem operasi windows 7 ultimate

b. Notepad ++

c. Microsoft Office

d. Microsoft Visio

e. Web Server XAMPP(Apache, $M y S Q L)$

f. Bahasa Pemogaraman HTML, PHP, SQL dan CSS

\section{Perancangan Sistem}

\section{Diagram Konteks}

Diagram konteks adalah gambaran sistem secara keseluruhan, hanya berisi satu proses yang menggambarkan sistem tersebut terhubung dengan entitas eksternal. Diagram konteks dari perancangan sistem dapat dilihat pada gambar sebagai berikut:

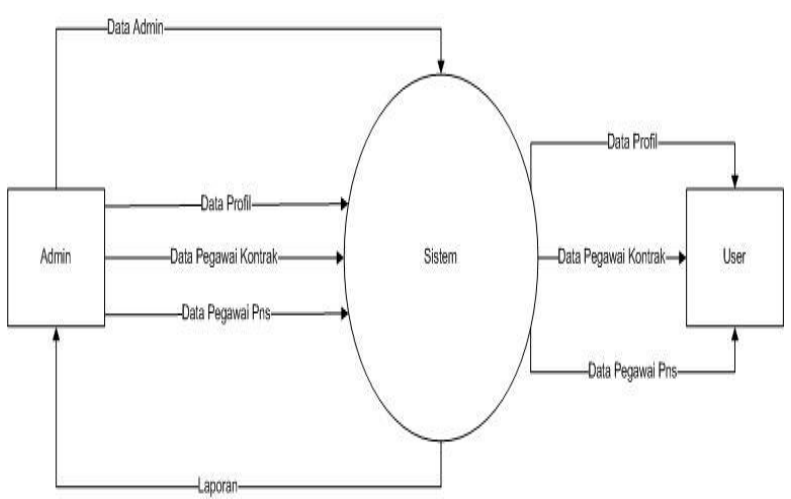

Gambar 3. Diagram Konteks

\section{DFD Level 1}

\section{Alat dan Bahan}

1. Perangkat Keras (Hardware)

a. Processor intel core 2 Duo

b. LCD LED HD 14.0"

c. Mainboard intel 


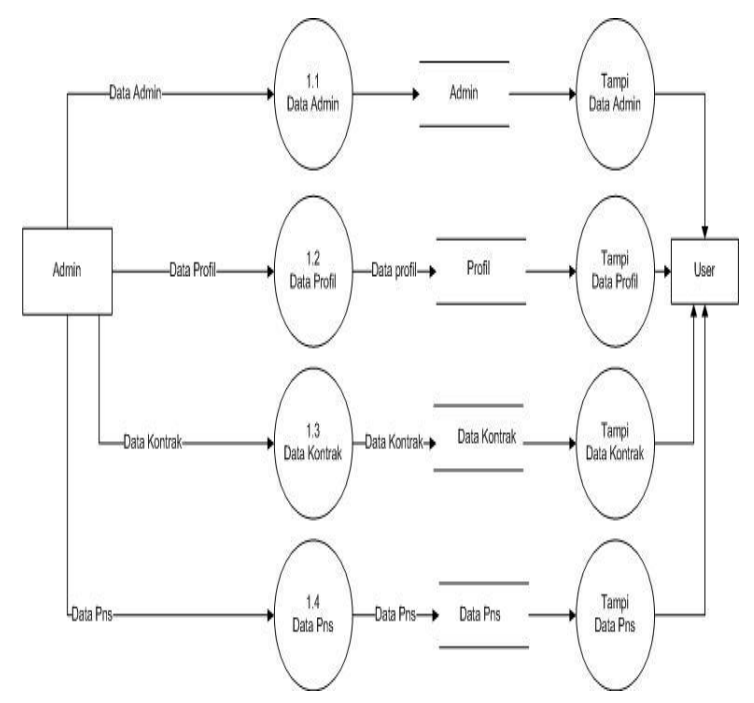

Gambar 4. Diagram Konteks

\section{ERD (entity relationship diagram)}

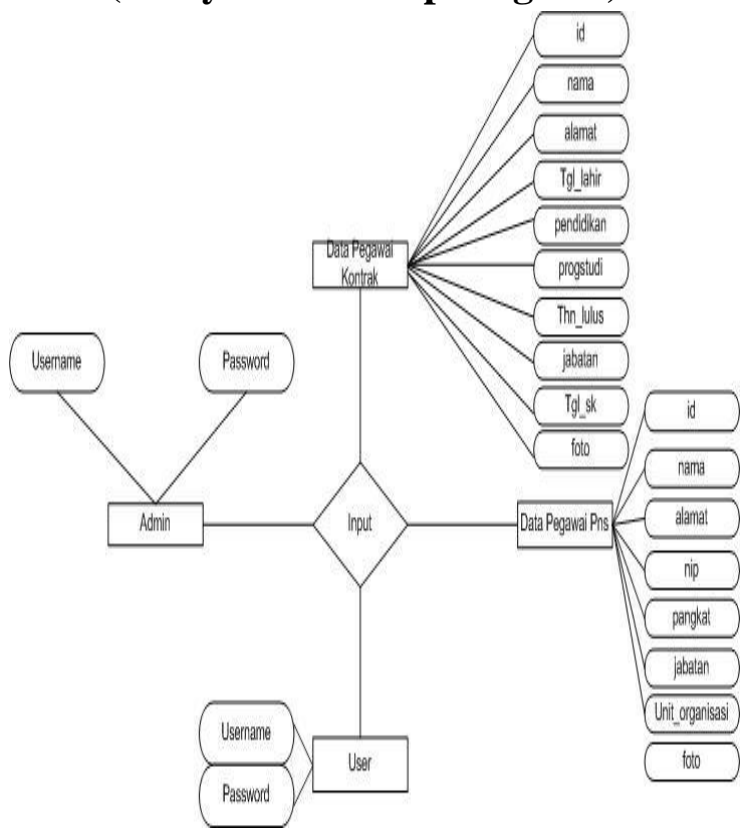

Gambar 5. Notasi

\section{Perancangan Tabel}

Tabel 1. Admin

\begin{tabular}{|l|l|l|l|l|}
\hline $\begin{array}{l}\text { Field } \\
\text { Nam } \\
\text { e }\end{array}$ & $\begin{array}{l}\text { Data } \\
\text { Type }\end{array}$ & $\begin{array}{l}\text { Fiel } \\
\text { d } \\
\text { Size }\end{array}$ & Keterangan & $\begin{array}{l}\text { Primar } \\
\text { K Key }\end{array}$ \\
\hline Id & Integer & 11 & $\begin{array}{l}\text { Penomoran(P } \\
\text { K) }\end{array}$ & $*$ \\
\hline User & $\begin{array}{l}\text { Varcha } \\
\text { r }\end{array}$ & 20 & $\begin{array}{l}\text { Username } \\
\text { Untok Login }\end{array}$ & \\
\hline Pass & $\begin{array}{l}\text { Varcha } \\
\text { r }\end{array}$ & 20 & $\begin{array}{l}\text { Password } \\
\text { Untuk Login }\end{array}$ & \\
\hline
\end{tabular}

Tabel 2. Profil

\begin{tabular}{|l|l|l|l|l|}
\hline $\begin{array}{l}\text { Nam } \\
\text { e }\end{array}$ & Type & $\begin{array}{l}\text { d } \\
\text { Size }\end{array}$ & $\mathbf{n}$ & y Key \\
\hline Id & Integer & 11 & $\begin{array}{l}\text { Penomoran } \\
\text { (PK) }\end{array}$ & $*$ \\
\hline Foto & $\begin{array}{l}\text { Varcha } \\
\mathrm{r}\end{array}$ & 50 & Foto & \\
\hline Isi & $\begin{array}{l}\text { Varcha } \\
\mathrm{r}\end{array}$ & 70 & Isi & \\
\hline
\end{tabular}

Tabel 3. Pegawai Kontrak

\begin{tabular}{|l|l|l|l|l|}
\hline $\begin{array}{l}\text { Field } \\
\text { Name }\end{array}$ & $\begin{array}{l}\text { Data } \\
\text { Type } \\
\text { Id }\end{array}$ & $\begin{array}{l}\text { Fiel } \\
\text { Size } \\
\text { r }\end{array}$ & $\begin{array}{l}\text { Keterang } \\
\text { an }\end{array}$ & $\begin{array}{l}\text { Primar } \\
\text { y Key }\end{array}$ \\
\hline Nama & $\begin{array}{l}\text { Varch } \\
\text { ar }\end{array}$ & 11 & $\begin{array}{l}\text { Penomora } \\
\text { n (PK) }\end{array}$ & $*$ \\
\hline Alamat & $\begin{array}{l}\text { Varch } \\
\text { ar }\end{array}$ & 20 & Alamat & \\
\hline Tgl_lahir & $\begin{array}{l}\text { Varch } \\
\text { ar }\end{array}$ & 20 & $\begin{array}{l}\text { Tanggal } \\
\text { lahir }\end{array}$ & \\
\hline $\begin{array}{l}\text { Pendidika } \\
\text { n }\end{array}$ & $\begin{array}{l}\text { Varch } \\
\text { ar }\end{array}$ & 14 & $\begin{array}{l}\text { Pendidika } \\
\text { n }\end{array}$ & \\
\hline $\begin{array}{l}\text { Prog_stud } \\
\text { i }\end{array}$ & $\begin{array}{l}\text { Varch } \\
\text { ar }\end{array}$ & 16 & $\begin{array}{l}\text { Program } \\
\text { studi }\end{array}$ & \\
\hline $\begin{array}{l}\text { Tahun_lul } \\
\text { us }\end{array}$ & $\begin{array}{l}\text { Varch } \\
\text { ar }\end{array}$ & 15 & $\begin{array}{l}\text { Tahun } \\
\text { lulus }\end{array}$ & \\
\hline Jabatan & $\begin{array}{l}\text { Varch } \\
\text { ar }\end{array}$ & 15 & Jabatan & \\
\hline Tgl_sk & $\begin{array}{l}\text { Varch } \\
\text { ar }\end{array}$ & 30 & $\begin{array}{l}\text { Tanggal } \\
\text { SK }\end{array}$ & \\
\hline Foto & Doubl \\
e & 50 & Foto & \\
\hline
\end{tabular}

Tabel 4. Pegawai PNS

\begin{tabular}{|l|l|l|l|l|}
\hline Field Name & $\begin{array}{l}\text { Data } \\
\text { Type }\end{array}$ & $\begin{array}{l}\text { Fiel } \\
\text { d } \\
\text { Size }\end{array}$ & $\begin{array}{l}\text { Keterang } \\
\text { an }\end{array}$ & $\begin{array}{l}\text { Prima } \\
\text { ry Key }\end{array}$ \\
\hline Id & $\begin{array}{l}\text { Intege } \\
\text { r }\end{array}$ & 11 & $\begin{array}{l}\text { Penomora } \\
\text { n (PK) }\end{array}$ & $*$ \\
\hline Nama & $\begin{array}{l}\text { Varch } \\
\text { ar }\end{array}$ & 15 & Nama & \\
\hline Alamat & $\begin{array}{l}\text { Varch } \\
\text { ar }\end{array}$ & 15 & Alamat & \\
\hline Nip & $\begin{array}{l}\text { Varch } \\
\text { ar }\end{array}$ & 13 & Nip & \\
\hline Pangkat & $\begin{array}{l}\text { Varch } \\
\text { ar }\end{array}$ & 14 & Pangkat & \\
\hline Jabatan & $\begin{array}{l}\text { Varch } \\
\text { ar }\end{array}$ & 16 & Jabatan & \\
\hline $\begin{array}{l}\text { unit_organi } \\
\text { sasi }\end{array}$ & $\begin{array}{l}\text { Varch } \\
\text { ar }\end{array}$ & 16 & $\begin{array}{l}\text { Unit } \\
\text { Organisas } \\
\text { i }\end{array}$ & \\
\hline Foto & $\begin{array}{l}\text { Varch } \\
\text { ar }\end{array}$ & 20 & Foto & \\
\hline
\end{tabular}




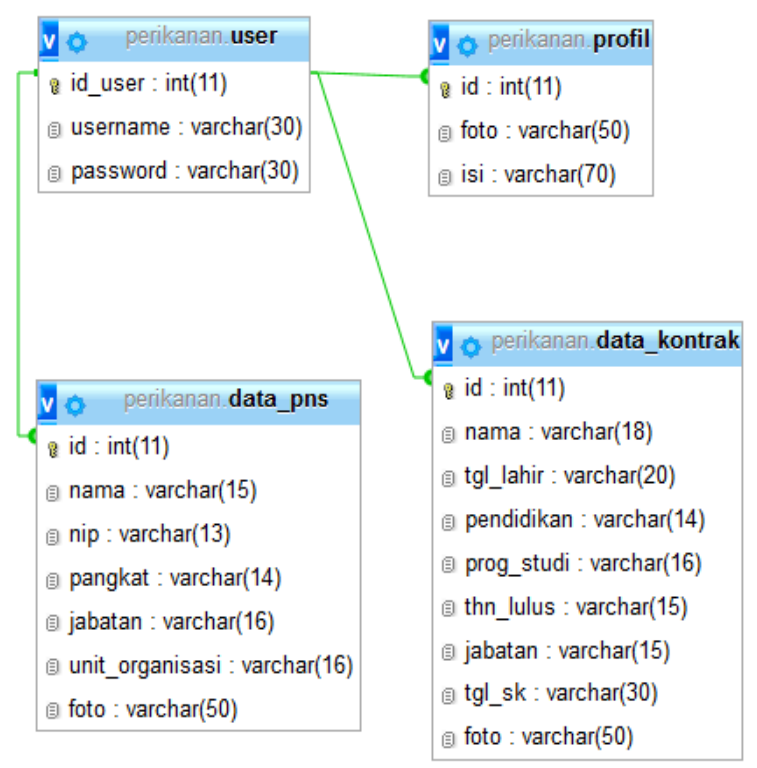

Gambar 6. Relasi Tabel

\section{IMPLEMENTASI DAN PEMBAHASAN} Halaman Profil

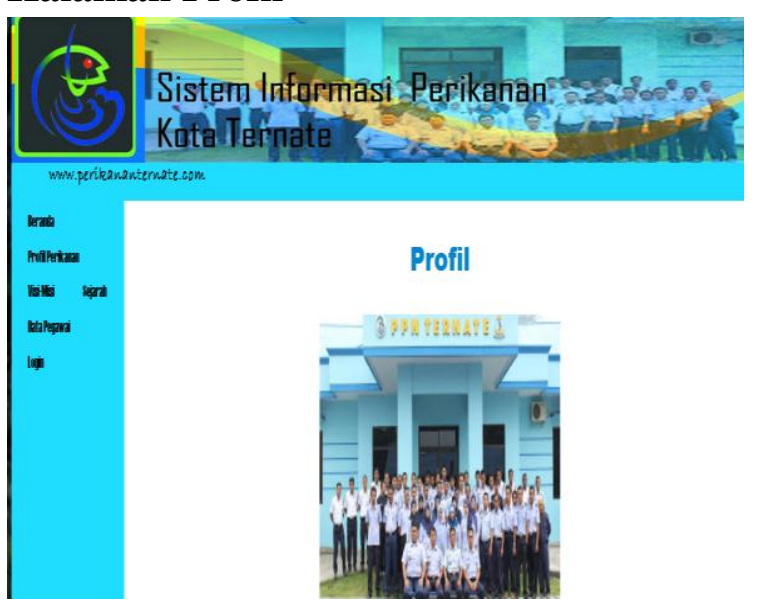

Gambar 7. Halaman Profil

\section{Login Admin}

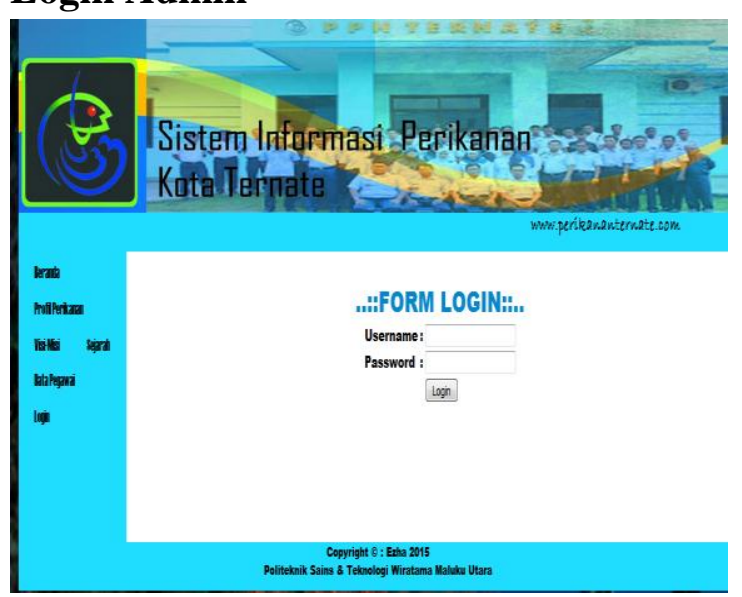

Gambar 8. login admin
Menu Input Pegawai Kontrak

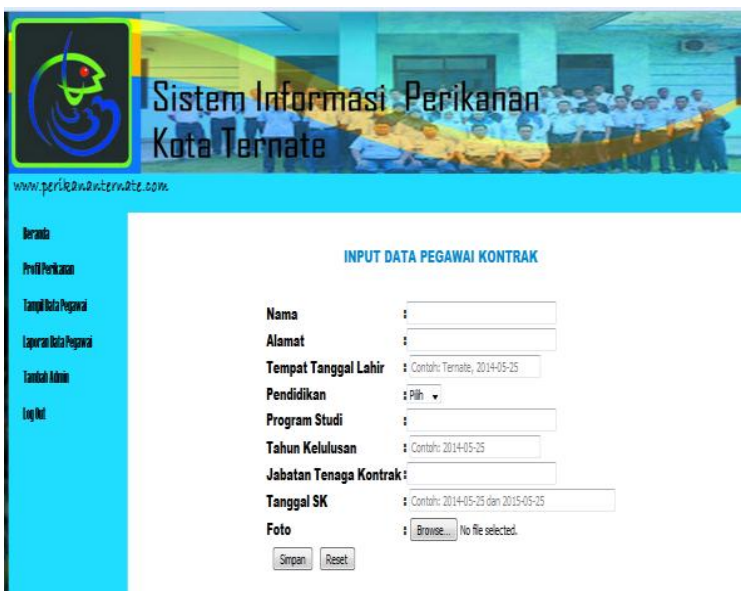

Gambar 9. Input Pegawai Kontrak

\section{Menu Input PNS}

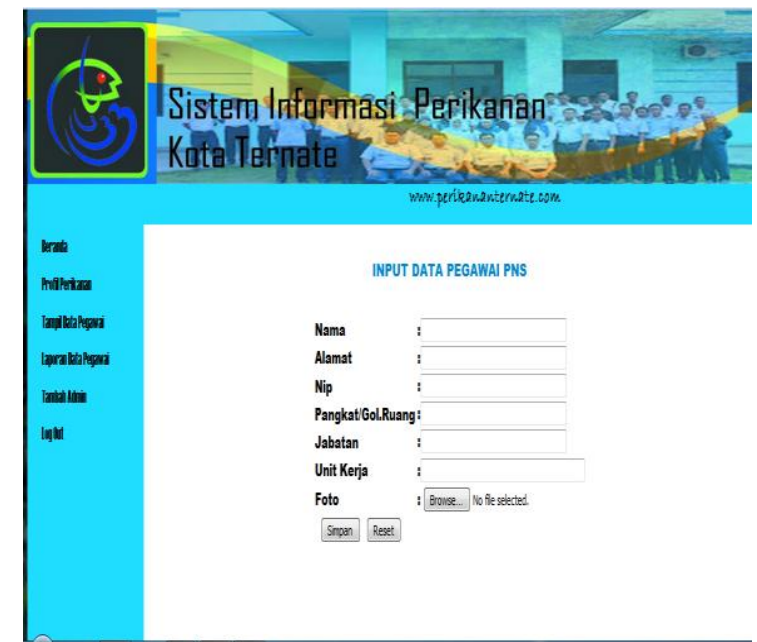

Gambar 10. Menu Input Kategori

\section{Form Cetak Laporan Data Pegawai}

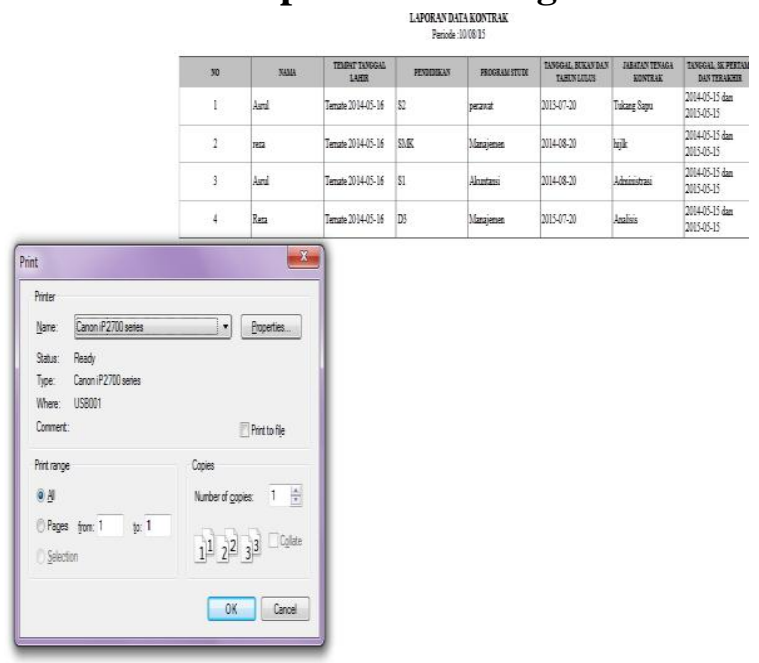

Gambar 11. Cetak Laporan Data PNS 


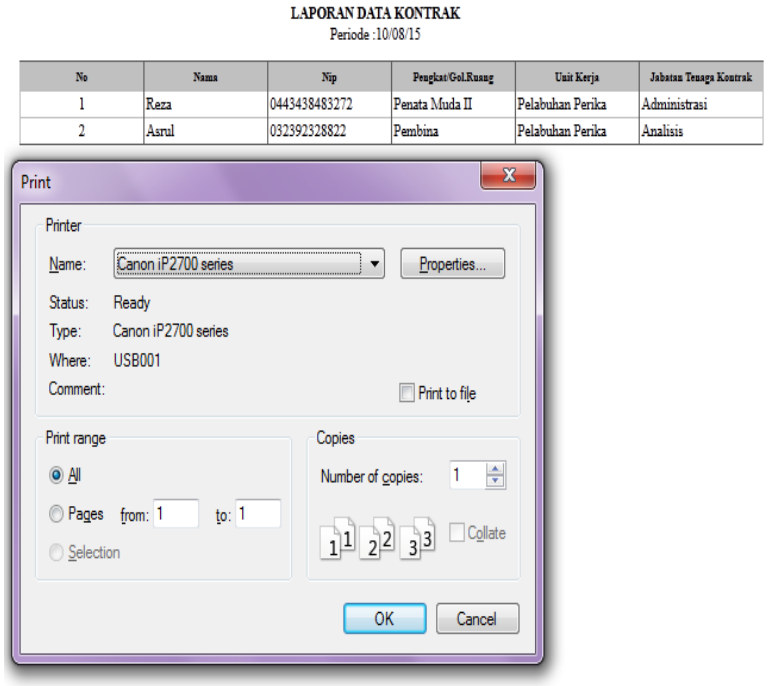

Gambar 12. Cetak Laporan Data Pegawai Kontrak

\section{KESIMPULAN}

Hasil Perancangan Sistem Informasi data Pegawai Berbasis Web pada Kementerian Kelautan dan Perikanan Ternate di simpulkan sebagai berikut:

1. Sistem ini di buat untuk mempermudah Membantu Kinerja admin dalam dalam mengelola data pegawai secara efesien

2. Sebagai media informasi kepada masyarakat tentang Kelautan dan Perikanan

\section{DAFTAR PUSTAKA}

Jogiyanto 2005. Pengenalan Sistem Informasi. AndiOfset, Yogyakarta

Moekijat. 2005. Pengantar Sistem Informasi Manajemen. Mandar Maju, Bandung.

Nugroho, Bunafit. 2008. Latihan Membuat Aplikasi Web PHP dan MySQL dengan Dreamweaver. Gava Media, Yogyakarta.

Mulyanto, Agus. 2009. Sistem Informasi Konsep dan Aplikasi. PustakaPelajar, Yogyakarta.

Al Fata Hanaf. 2007. Analisis \& Perancangan Sistem Informasi. AndiOfset, Yogyakarta.

Tata Sutabri. 2012. Analisis Sistem Informasi. Andi. Yogyakarta
Saputra, H dan Kawistara, S. 2014. Pemograman Web. Informatika, Bandung.

Nofyat, Adelina Ibrahim, Arisandy Ambarita, Sistem Informasi Pengaduan Pelanggan Air Berbasis Website pada PDAM Kota Ternate, IJIS-Indonesian Journal On Information System, Volume 3 Nomor 1 April Tahun 2018, e-ISSN 25486438, $p$-ISSN 2614-7173

Vivin Ambar, Arisandy Ambarita, Sistem Informasi Pengolahan Data Kelulusan Siswa Non-Formal Berbasis Web Pada Dinas Pendidikan Nasional Kota Ternate. IJIS-Indonesian Journal on Information System, Volume 2 Nomor 1 April Tahun 2017, ISSN 2548-6438 